\title{
Efficiency and Effectiveness of Gamma Rays and Sodium Azide in Sesbania cannabina Poir.
}

\author{
Girjesh Kumar, and Nitisha Srivastava* \\ Plant Genetics Laboratory, Department of Botany, \\ University of Allahabad-211002, U.P., India \\ Received October 14, 2012; accepted March 10, 2013
}

\begin{abstract}
Summary Mutagenic effectiveness and efficiency is an important factor for the selection of a mutagen for a mutation breeding program. Mutagenic effectiveness is a measure of the frequency of mutations induced by a unit mutagen dose, while mutagenic efficiency is a measure of the proportion of mutations in relation to undesirable changes such as lethality, sterility, meiotic aberrations etc. The present study envisages the mutagenic effectiveness and efficiency of individual and combined treatments of chemical and physical mutagens i.e. sodium azide (individual), gamma rays (individual) and sodium azide+gamma ray (combined). For the individual treatment of sodium azide, the seeds of the Sesbania cannabina variety ND-1 were treated with $0.5 \%$ solution of sodium azide (SA) for four different time durations, i.e. $3,5,7$, and $9 \mathrm{~h}$, and for the individual treatment of gamma rays, dry and healthy seeds were treated with $20,40,60$, and $80 \mathrm{Kr}$ doses of gamma rays. For the combined treatment, the seeds were exposed to four different doses of gamma rays $(20,40,60$, and $80 \mathrm{Kr}$ ) and after irradiation seeds were treated with $0.5 \%$ solution of sodium azide for $3 \mathrm{~h}$. After treatment, seeds subjected to individual and combined treatment were sown in randomized block design to raise the $\mathrm{M}_{1}$ generation and a study was conducted on germination percentage, survival percentage, pollen fertility percentage, and chromosomal aberrations at different doses of the individual and combined treatments.
\end{abstract}

Key words Sesbania cannabina, Mutagens, Sodium azide, Gamma rays.

Mutations are the tools used by the geneticist to study the nature and function of genes which are the building blocks and basis of plant growth and development, thereby producing raw materials for the genetic improvement of economic crops. Mutation breeding is expected to make a contribution primarily as an important adjunct to the conventional breeding approach. A large number of desirable varieties have been developed through mutation breeding in field and horticulture crops. The technology of mutation induction has become an established tool in plant breeding in order to supplement existing germplasms and to improve specific traits in cultivars. Varieties with better genotype and phenotype characters have been revealed to farmers as a result of induced mutations which have been used directly as new cultivars or they can be used in cross breeding programs (Gottschalk and Wolff 1983, Micke et al. 1987). For the Sesbania cannabina, thus far very limited work has been carried out using gamma rays alone or in combination with chemical mutagens for the improvement of quantitative and qualitative characters.

Sesbania cannabina is a quick growing succulent green manure crop and widely adaptable to adverse climatic conditions such as drought, waterlogging, high salinity, etc. It belongs to the family Fabaceae and its major agronomic use has been as green manure to improve the production of food crops, as it improves the soil fertility. In 1983, Bhatti et al. reported that Sesbania green ma-

\footnotetext{
*Corresponding author, e-mail: srivastava_nitisha@yahoo.com

DOI: $10.1508 /$ cytologia. 78.81
} 
nuring substantially improves grain yield, by up to $72 \%$. The induction of mutations is an important approach to creating genetic variability in plants. Genetic variability is fundamental to successful breeding programs in vegetatively and sexually propagated plants. The mutants so produced facilitate the isolation, identification, and cloning of genes used in designing crops with improved yields, increase stress tolerance, longer shelf life, and reduced agronomic input (Ahloowalia and Maluszynski 2001).

Physical and chemical mutagens have been successfully used to evolve new varieties with improved economic traits (Mahla et al. 1990, Rehman 1990, Kumar 1972). The combination of physical and chemical treatments used in many crops (Singh and Chaturvedi 1987, Chang and Gao 1988, Rakow and Raney 2003) has indicated there to be a higher frequency of mutations in combined treatments as compared with individual treatments.

Sodium azide has been reported to be mutagenic in a large number of crop species. Sodium azide $\left(\mathrm{NaN}_{3}\right)$ is a common laboratory chemical and is widely used in industry, agriculture, medical practice, and organic synthesis research. It is a common bactericide, pesticide, and industrial nitrogen gas generator, and known to be highly mutagenic in several organisms, including plants and animals (Rines 1985, Veleminsky and Anglis 1987, Raicu and Mixich 1992). Gamma rays are an energetic form of electromagnetic radiations produced by radioactivity or other nuclear or sub atomic processes with a wavelength of $10^{-11}$ to $10^{-7} \mathrm{~cm}$. Gamma radiation has been reported to have beneficial effects on many crops. In African violets (Saintpaulia ionantha H. Wendl.), gamma radiation at $15 \mathrm{~Gy}$ improved the plant architecture of the mutants (Senevirante and Wijesundara 2007). In wheat, gamma radiation improved germination, plant height, grain per plant, and grain yield at 200 Gy (Jamil and Khan 2002) and at 300 to 400 Gy (Irfaq and Nawab 2001). The present study was undertaken to study the effect of physical and chemical mutagens on different parameters of Sesbania cannabina.

Materials and methods

\section{Procurement of seeds}

Seeds of Sesbania cannabina variety ND-1 were obtained from Sunn Hemp Research Station, Pratapgarh, India.

\section{Treatment of sodium azide}

Dry and healthy seeds were soaked in water for $14 \mathrm{~h}$. Soaked seeds were then treated with $0.5 \%$ solution of sodium azide (SA) for four different time durations $(3,5,7$, and $9 \mathrm{~h}$ ). After treatment, the seeds were washed in running water to remove the SA. After that, the treated seeds, together with the control seeds, were sown in triplicate to raise the $\mathrm{M}_{1}$ generation.

\section{Treatment of Gamma rays}

Dry and healthy seeds were irradiated at four doses of gamma rays, viz. 20, 40, 60, and $80 \mathrm{Kr}$, using a ${ }^{60} \mathrm{CO}$ source at the National Botanical Research Institute (N.B.R.I.), Lucknow. The dose rate was $18 \mathrm{Krad} / \mathrm{s}$ with gamma chamber- 900 model (the chamber was supplied by Bhabha Atomic Research Centre (BARC), Mumbai). After irradiation, the seeds were sown in their respective pots in triplicate to raise the $\mathrm{M}_{1}$ generation. Unradiated seeds were also sown as a control set.

\section{Combined treatment of gamma ray and sodium azide}

For the combined treatment, the dry and healthy seeds were irradiated at four doses of gamma rays, viz. 20, 40, 60, and $80 \mathrm{Kr}$, using a ${ }^{60} \mathrm{CO}$ source at the National Botanical Research Institute (N.B.R.I.), Lucknow. The dose rate was $18 \mathrm{Krad} / \mathrm{s}$ with a gamma chamber-900 model. After irradiation, the seeds were treated with $0.5 \%$ solution of sodium azide for $3 \mathrm{~h}$. After $3 \mathrm{~h}$, the seeds were 
washed in running water to remove the traces of SA and sown in their respective pots to raise the $\mathrm{M}_{1}$ generation.

\section{Field work}

Data for germination and survival percentages were taken after 15 and $30 \mathrm{~d}$ respectively. On the onset of budding, the young floral buds were fixed in Carnoy's fixative $(1: 3$, glacial acetic acid: abs. alcohol) in their respective bottles for $24 \mathrm{~h}$ and then stored in $70 \%$ ethyl alcohol in the refrigerator and were then used for cytogenetical analysis.

\section{Cytological studies}

Slides were prepared using the anther squash technique. Anthers were squashed in $2 \%$ acetocarmine. Slides were observed under the microscope to observe different meiotic stages and various chromosomal aberrations and data were taken for chromosomal aberrations of each treated set as well as for each control set.

\section{Results}

Effect of individual and combined treatments of SA and gamma rays on germination, survival and pollen fertility percentages of Sesbania cannabina

From Table 1, it is clear that seed germination decreases with the increasing dose of treatment in the individual treatments as well as in the combined treatment, although the rate of reduction in germination percentage was higher in the individual treatment of gamma rays as compared to the combined treatment and the individual treatment of sodium azide. Control exhibited $100 \%$ germination and this was reduced to $30 \%$ at the highest dose of gamma rays $(80 \mathrm{Kr})$, while it was $50 \%$ at the highest dose of the combined treatment. Unlike germination, survival percentages were $100 \%$ for all doses of the individual treatment (SA), while in case of the gamma rays individual treatment survival percentage was reduced to $25 \%$, and in the combined treatment, survival percentage was $100 \%$ at 2 lower doses and at the highest dose i.e. $80 \mathrm{Kr}+\mathrm{SA}$, it was reduced to $58.33 \%$. Table 1 shows pollen fertility at different doses of treatment of the individual and combined treatments of SA and gamma rays. The control set exhibited the highest pollen fertility, viz. $94.16 \%$, and fertility

Table 1. Effect of individual and combined treatment of SA and gamma rays on germination, survival, and pollen fertility percentages of Sesbania cannabina.

\begin{tabular}{cccc}
\hline \hline Mutagenic treatment & Germination percentage & Survival percentage & $\begin{array}{c}\text { Pollen fertility } \\
\text { (percentage) }\end{array}$ \\
\hline Control & 100 & 100 & 94.16 \\
SA & & & \\
$3 \mathrm{~h}$ & 90 & 100 & 89.94 \\
$5 \mathrm{~h}$ & 80 & 100 & 83.09 \\
$7 \mathrm{~h}$ & 70 & 100 & 80.76 \\
$9 \mathrm{~h}$ & 70 & 100 & 76.27 \\
Gammas rays & & & 81.66 \\
$20 \mathrm{Kr}$ & 60 & 100 & 80.33 \\
$40 \mathrm{Kr}$ & 50 & 90 & 74.66 \\
$60 \mathrm{Kr}$ & 40 & 75 & 70.00 \\
$80 \mathrm{Kr}$ & 30 & 25 & 82.33 \\
Gamma rays+SA $(0.5 \%)$ & & 100 & 77.50 \\
$20 \mathrm{Kr}+\mathrm{SA}$ & 70 & 100 & 74.70 \\
$40 \mathrm{Kr}+\mathrm{SA}$ & 70 & 83.33 & 70.34 \\
$60 \mathrm{Kr}+\mathrm{SA}$ & 60 & 58.33 & \\
$80 \mathrm{Kr}+\mathrm{SA}$ & 50 & & \\
\hline
\end{tabular}



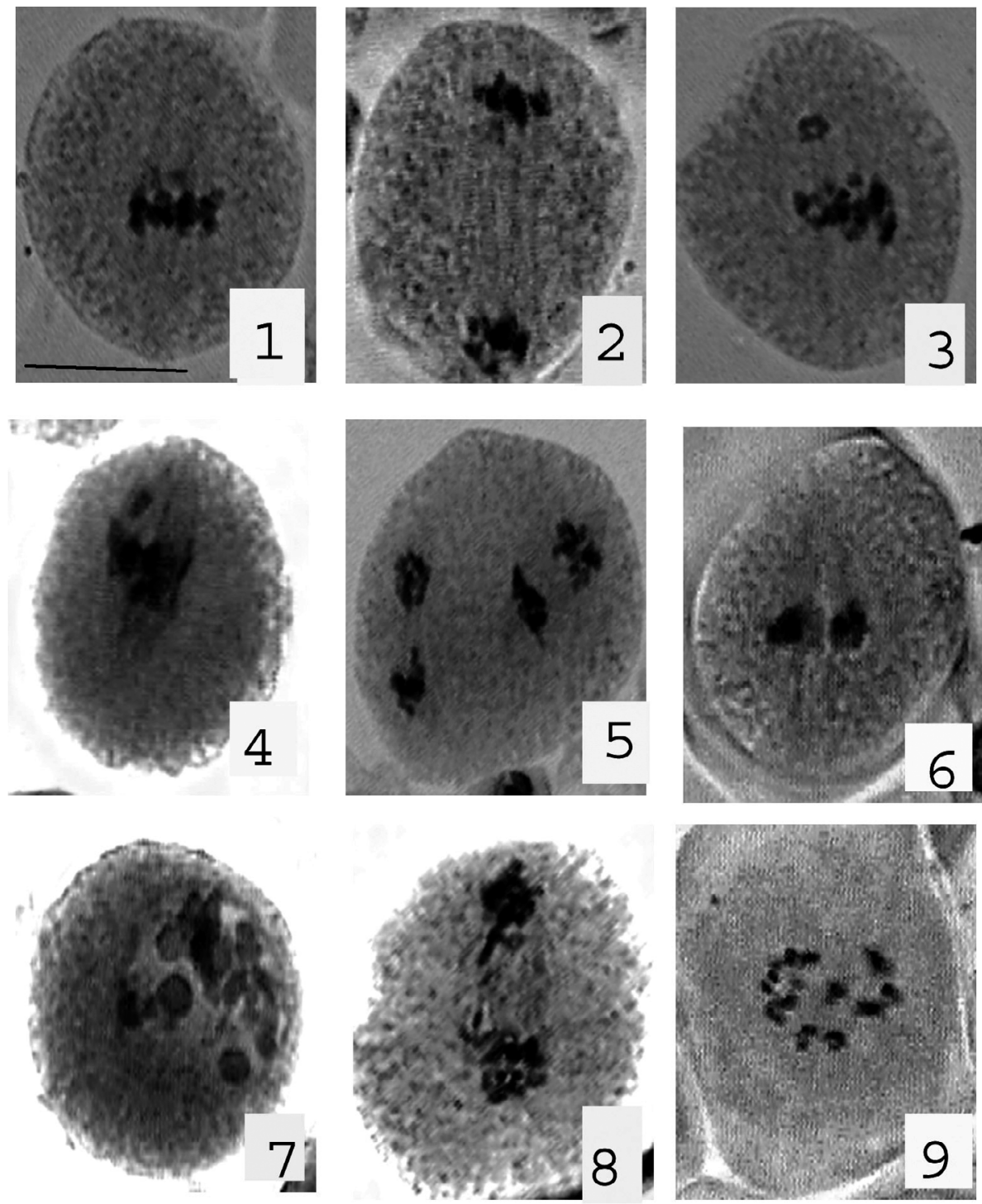

Figs. 1-9. 1. Normal metaphase $(n=12)$, 2. Normal anaphase $(12: 12)$, 3. Precocious movement at metaphase I with ring formation at the dose of $9 \mathrm{~h} \mathrm{SA}, 4$. Precocious movement with Unorientation at metaphase I at the dose of $60 \mathrm{Kr}+\mathrm{SA}$, 5. Unorientation at anaphase II at the dose of $60 \mathrm{Kr}$ gamma rays, 6. Secondary association at metaphase I at the dose of $5 \mathrm{~h} \mathrm{SA,} \mathrm{7.} \mathrm{Multinucleate} \mathrm{con-}$ dition at the dose of $80 \mathrm{Kr}+\mathrm{SA}, 8$. Bridge at anaphase I at the dose of $80 \mathrm{Kr}$ gamma rays, 9. Scattering at metaphase I at the dose of $3 \mathrm{~h} \mathrm{SA}$. Scale bar $=10 \mu \mathrm{m}$.

showed a decreasing trend in parallel with the dosage increase in individual and combined treatments. The lowest pollen fertility was observed at $80 \mathrm{Kr}$, which was $70 \%$, while at the highest dose of the combined treatment it was $70.34 \%$.

\section{Effect of SA on microsporogenesis of Sesbania cannabina}

Analysis of pollen mother cells (PMCs) of the control set indicated 12 perfect bivalents $(n=12)$ at metaphase (Fig. 1). At anaphase I (Fig. 2), the PMCs of the control plants exhibited normal 12:12 segregation. The spectrum of various meiotic anomalies and the total number of abnor- 


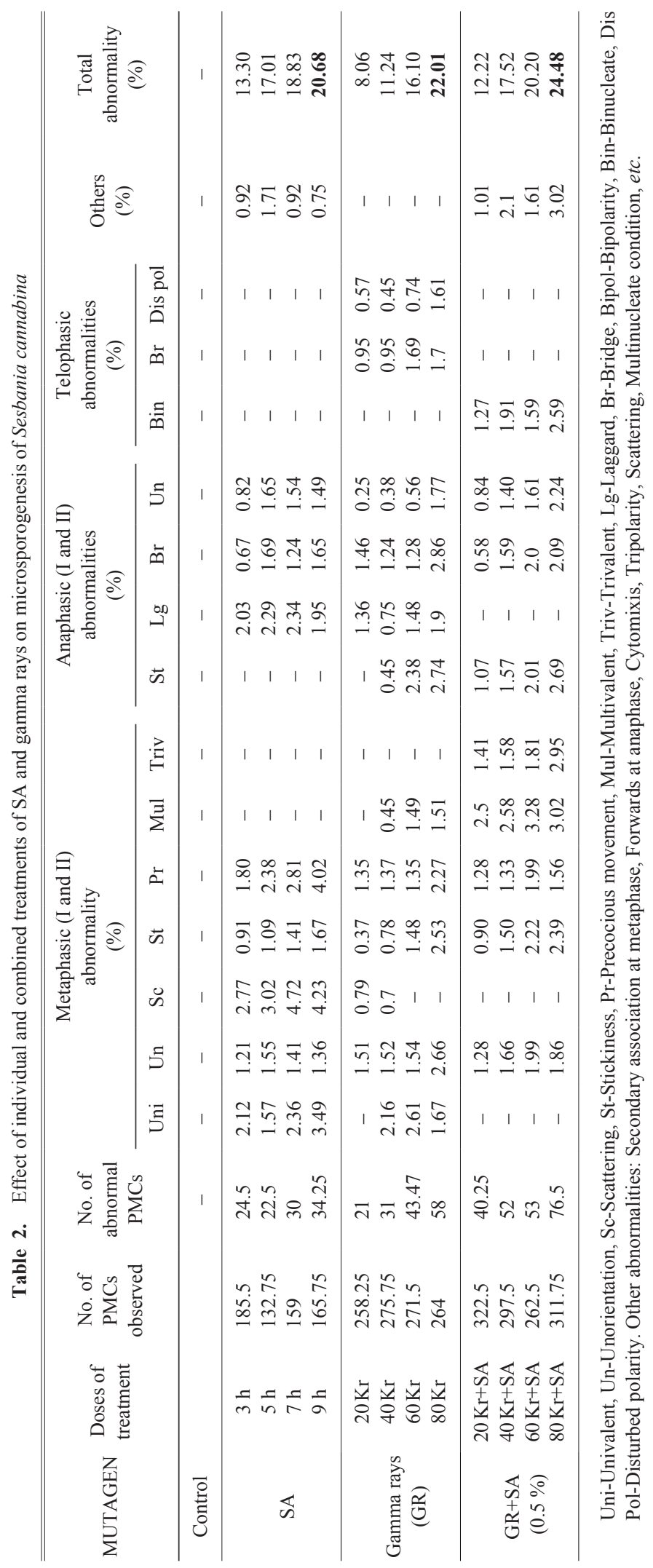


mal PMCs has been summarized in Table 2. The most frequent aberrations were: scattering at metaphase, precocious movement at metaphase, univalents at metaphase, and unorientation at anaphase (Fig. 5). Scattering at metaphase was found to be highest (4.72\%) at the $7 \mathrm{~h}$ dose of treatment and the lowest $(3.02 \%)$ at the $5 \mathrm{~h}$ dose of treatment. The highest frequency of precocious movement (Figs. 3, 4) was observed at $9 \mathrm{~h}$, where it found to be $4.02 \%$. Univalents were also found to be highest at $9 \mathrm{~h}$, viz. $3.49 \%$, and the lowest at the $5 \mathrm{~h}$ dose of treatment, viz. $1.57 \%$. Among anaphasic aberrations, laggards were observed in higher frequency and were found to be the most frequent at $7 \mathrm{~h}$ $(2.34 \%)$. The total abnormality percentage showed an exponential increase along with the increasing dosage of treatment and was observed to be 13.30 and $20.68 \%$ at the $3 \mathrm{~h}$ and $9 \mathrm{~h}$ doses of treatment, respectively.

\section{Effect of gamma rays on microsporogenesis of Sesbania cannabina}

The plants in the gamma irradiated sets exhibited various types of meiotic aberrations at each phase of meiosis. It is evident from Table 2 that different types of aberrations increased along with the increase in gamma ray dose. Gamma rays induced various types of chromosomal aberrations, such as univalents, precocious movement, multivalent, unorientation, laggards, bridges, stickiness, disturbed polarity, etc. The most prominent abnormalities were bridges at anaphase, stickiness at anaphase, unorientation at metaphase, stickiness at metaphase, and precocious movement at metaphase. Bridges at anaphase were found at the highest frequency at the $80 \mathrm{Kr}$ dose, i.e. $2.86 \%$. Bridges were observed at both anaphase and telophase but the frequency was highest at anaphase. Univalents and multivalents at metaphase were prominent at higher doses, while absent at $20 \mathrm{Kr}$. Scattering at metaphase I (Fig. 9) was observed only at the 2 lower doses and was absent at $60 \mathrm{Kr}$ and $80 \mathrm{Kr}$. Stickiness at metaphase and anaphase was found to be most frequent at $80 \mathrm{Kr}$ doses of treatment, at $2.53 \%$ and $2.74 \%$, respectively. Among telophasic aberrations, bridges (Fig. 8) were more frequent than disturbed polarity (Table 2 ). The total abnormality percentage was observed to be highest at $80 \mathrm{Kr}$ doses of treatment and was found to be $22.01 \%$ which was comparatively higher than that of the individual treatment of SA (Table 2).

\section{Effect of gamma rays + SA on microsporogenesis of Sesbania cannabina}

The spectrum of various meiotic anomalies induced by the combined treatment of SA and gamma rays has been summarized in Table 2 . The total abnormality percentage showed an exponential increase along with the increase in treatment dosage. The most frequent chromosomal aberrations were multivalent formations at metaphase, trivalents at metaphase, and binucleates at telophase. Multivalents were found to be most frequent at $60 \mathrm{Kr}+\mathrm{SA}(3.28 \%)$, while at the highest dose of $80 \mathrm{Kr}+\mathrm{SA}$ the frequency was $3.02 \%$. Binucleate cells were observed during telophase and were found to be most frequent $(2.59 \%)$ at the $80 \mathrm{Kr}+\mathrm{SA}$ dose. Metaphasic aberrations were more prominent than anaphasic aberrations. Instances of stickiness at metaphase and anaphase increased in parallel with higher doses of treatment. The total abnormality percentage at the lowest dose of $20 \mathrm{Kr}+\mathrm{SA}$ was $12.22 \%$ and was $24.48 \%$ at the highest dose ( $80 \mathrm{Kr}+\mathrm{SA})$, which was comparatively higher than the percentage seen in the individual treatments (Table 2).

\section{Discussion}

In the present experiment, the effect of individual treatments of SA and of gamma rays and of a combined treatment of SA and gamma rays on germination, survival, and pollen fertility has been studied. In all cases of treatment, as the treatment dose increases, the percentage value of these indices decreases. Among the treated sets, maximum germination was found at the $3 \mathrm{~h}$ dose of SA and this then decreased up to $50 \%$ at the highest dose of the combined treatment. These results are in line with the results of (Khan and Al-Qurainy 2009) who performed his experiment on Eruca sa- 
tiva. The reduction in germination percentages may be attributed to the delay or inhibition of physiological and biological processes necessary for seed germination, which include enzyme activity (Chrispeeds and Varner 1976), hormonal imbalance (Khan and Al-Quainy 2009), and the inhibition of mitotic process (Ananthaswamy et al. 1971). The inhibitory effect of $\mathrm{NaN}_{3}$ on germination could be azide anions which are strong inhibitors of cytochrome oxidase, which in turn inhibits oxidative phosphorylation (Kleinhofs et al. 1978). In addition, it is a potent inhibitor of the proton pump and alters the mitochondrial membrane potential (Zhang 2000). These effects together may hamper ATP biosynthesis resulting in the decreased availability of ATP, which may slow the germination rate and reduce the germination percentage. Various doses of treatment affected the survivability of seedlings in a dose dependent manner as shown in Table 1. According to Sato and Gaul (1967) and Natrajan and Shivshankar (1965), the reduction in seedling survival can be attributed to cytogenetic damage and physiological disturbances caused by mutagen treatment. Thus, the probable reason of the drop in seedling survivability may be the hindrance caused by the SA and gamma rays on different metabolic pathways of the cells. Similar findings have also been reported by Rachovska and Dimova (2000) in wheat, Akhaury et al. (1996) and Ilbas et al. (2005) in barley, Adamu and Aliyu (2000) in tomato, Khan et al. (2004) in mungbean, Al-Qurainy (2009) in Eruca sativa, and Mostafa (2011) in sunflower.

Pollen fertility is an index of meiotic behavior. The more frequent the chromosomal aberrations, the greater the pollen sterility, as in the case of the present experiment, in which a reduction in pollen fertility was observed in both cases, i.e. in the individual treatments as well as the combined treatment; this was found to be in a dose dependent manner. Similar results were also reported by Reddi (1977) and Bhat et al. (2007). They reported that pollen sterility was the result of interchanges of segments between non-homologous chromosomes and considered that the presence of laggards, univalents, micronuclei, and stickiness was closely associated with pollen sterility.

Analysis of microsporogenesis was done to study the chromosomal behavior at meiosis in order to correlate it with fertility of the species. The meiotic study of pollen mother cells of control exhibited a normal diploid status with chromosome number $(n=12)$, i.e. 12 bivalents at metaphase I and normal separation $(12: 12)$ at anaphase I. Compared to the control sets, the treated sets showed various types of chromosomal aberrations. Different types of metaphasic, anaphasic, and telophasic aberrations were scored at all doses of the individual and combined treatments. Similar types of aberrations were also reported by many researchers in different plant materials after treatment with different mutagens. A dose dependent enhancement in the meiotic aberration due to the effect of different mutagens has also been studied by various investigators like Ahmad (1993), Kumar and Dubey (1998), Dhamyanthi and Reddy (2000), Ignacimuthu and Babu (1989), Ahmad and Yasmin (1992), Patil and Bhat (1992), Singh (1992), Misra et al. (2001). During the cytological observations of the individual and combined treatments of the present study, it was found that the combined treatment was more effective and efficient in inducing chromosomal aberrations.

Sinha and Godward (1972) suggested that paracentric inversions may lead to the formation of chromatin bridges at anaphase and telophase stages of meiosis. Bridge formation may occur due to the failure of chiasmata in a bivalent to terminalize and the chromosome stretched between the poles (Saylor and Smith 1996). Single and multiple chromosome bridges may be due to the occurrence of dicentric chromosomes formed as a result of breakage fusion bridge cycles (McClintok 1941). Chromosomal stickiness may be due to genetic or environmental factors (Consolaro et al. 1996) and several agents have been reported to cause stickiness of chromosomes (Souza and Pagliarini 1996). Laggards observed during the present cytological studies might have originated due to delayed terminalization, stickiness of chromosomal ends, or because of failure of the chromosomal movements (Jayabalan and Rao 1987, Soheir et al. 1989). Disturbed polarity observed during anaphase may be due to spindle disturbance (Bhat et al. 2007). Jayabalan and Rao (1987) suggested that stickiness might be due to disturbance in the cytochemically balanced reaction. Tarar 
and Dnyansagar (1980) have reported that stickiness at meiosis is due to the depolymerisation of nucleic acids caused by mutagenic treatments; or, it may be due to chemically induced stickiness to direct action of mutagens on the histone proteins leading to improper folding of DNA (Gaulden 1987). Bridges are also induced by many other mutagens, such as methyl methane sulphonate (Khan and Al-Qurainy 2009), and SA (Srivastava and Kapoor 2008), etc. Precocious movement of chromosomes may be due to spindle dysfunction. Kumar and Rai (2007) reported that precocious chromosome migration to the poles may be due to the formation of univalent chromosomes at the end of prophase I or to precocious chaisma terminalization at diakinesis or metaphase. Unorientation at metaphase and scattering of chromosomes may be due to the inhibition of spindle formation or the destruction of spindle fibers formed (Kumar and Rai 2007).

Increasing mutation frequency is a very important aspect for bringing about improvements in the efficiency of mutation breeding programs. SA and gamma rays have been demonstrated to induce mutations by different mechanisms. Combinations of these mutagens in appropriate sequences have been shown to cause a synergistic increase in mutation frequency. Combined treatments induced a higher mutation frequency with relatively less injury, thus resulting in higher mutation efficiency, thereby offering more opportunities for selection in mutation breeding practice. Thus, in the present experiment, the combined treatment of gamma rays and SA appears to be most effective mutagenic treatment for the induction of mutations in Sesbania cannabina to increase yield component traits and to aid the selection of improved populations.

\section{Acknowledgements}

The authors are thankful to Sunn Hemp Research Station, Pratapgarh, U.P., India, for providing seeds and Head, Floriculture Section, NBRI, Lucknow, for gamma irradiation of the seeds. The authors are also thankful to all members of Plant Genetics Laboratory for their valuable suggestions and cooperation.

\section{References}

Adamu, A. K., and Aliyu, H. 2000. Morphological effects of sodium azide on tomato (Lycopersicon esculentum Mill). Science World Journal 2: 9-12.

Ahloowalia, B. S., and Maluszynski, M. 2001. Induced Mutation. A new paradigm in plant breeding. Euphytica 118(2): $167-173$.

Ahmad, S. 1993. Meiotic studies in two cultivars of Cicer arietinum L. after gamma irradiation. Cytologia 58: 61-65.

Ahmed, S., and Yasmin, R. 1992. Effects of Methyl Parathion and Tri-miltox on the mitosis of Allium cepa. Cytologia 57: 155-160.

Akhaury, S. B., Sinha, A. N., and Sinha, A. K. 1996. The effectiveness and efficiency of chemical mutagens on biological parameters in hull-less variety of Hordeum vulgare (L.) Karan 16. Neo Botanica 4: 1-5.

Al-Qurainy, F. 2009. Effects of sodium azide on growth and yield traits of Eruca sativa (L.). World Appl Sci J 7: $220-226$.

Ananthaswamy, H. M., Vakil, V. K., and Shrinivas, A. 1971. Biological and physiological changes in gamma irradiated wheat during germination. Radiation Botany 11: 1-12.

Bhat, T. A., Sharma, M., and Anis, M. 2007. Comparative analysis of meiotic aberrations induced by diethylsulphonate and sodium azide in broad bean (Viciafaba L). Asian J. Plant Sci. 6: 1051-1057.

Bhatti, H. M., Yasin, M., and Rashid, M. 1983. Evaluation of Sesbania green manuring in rice-wheat rotation. In: Malik, K. A., Maqvi, M., and Aleem, M. I. H. (eds.). Proceedings of the International Symposium on Nitrogen and the Environment; Lahore, Pakistan. Nuclear Institute for Agriculture and Botany, Faisalabad.

Chang, X., and Gao, M. 1988. Biological and genetic effects of combined treatments of Sodium azide, gamma rays and EMS in barley. Environ. Exp. Bot. 28(4): 281-288.

Chrispeeds, M. J., and Varner, J. E. 1976. Gibberelic acid induced synthesis and release of $\alpha$-amylase and ribonuclease by isolated barley aleurons layers. Plant Physiol. 42: 346-406.

Consolaro, M. E. L., Pagliarini, M. S., and Chaves, L. J. 1996. Meiotic behavior, pollen fertility and seed production in Brazilian populations of Centella asiatica (L.)Urban (Umbelliferae). Cytologia 61: 375-381.

Dhamayanthi, K. P. M., and Reddy, V. R. K. 2000. Cytogenetic effects of gamma rays and ethylmethane sulphonate in chili 
peper (Capsicum annuum L.). Cytologia 65: 129-133.

Gaulden, M. E. 1987. Hypothesis: Some mutagens directly alter specific chromosomal proteins (DNA topoisomerase II and peripheral proteins) to produce chromosome stickiness, which causes chromosome aberrations. Mutagenesis 2: $357-365$.

Gottschalk, W., and Wolff, G. 1983. Induced mutation in plant breeding. Monograph on theoretical and applied genetics. Springer Verlag.

Ignacimuthu, S., and Babu, C. R. 1989. Induced chromosomal abnormality and pollen sterility in wild and cultivated urd and mung beans. Cytologia 51(1): 159-167.

Ilbas, A., Eroglu, Y., and Eroglu, H. E. 2005. Effects of the application of different concentrations of $\mathrm{NaN}_{3}$ for different times on the morphological and cytogenetic characteristics of barley (Hordeum vulgare L.) seedlings. J Integr Plant Biol 47: 1101-1106.

Irfaq, M., and Nawab, K. 2001. Effect of $\gamma$ irradiation on some morphological characteristics of three wheat (Triticum aestivum L.) cultivars. J. Biol. Sci. 1: 935-937.

Jamil, M., and Khan, U. Q. 2002. Study of genetic variation in yield components of wheat cultivar bukhtwar-92 as induced by $\gamma$ radiation. Asian J. Plant Sci. 1: 579-580.

Jayabalan, N., and Rao, G. R. 1987. Gamma radiation induced cytological abnormalities in Lycopersicon escculentum Mull. Var. Pusa Ruby. Cytologia 52: 1-4.

Khan, S., and Al-Qurainy, F. 2009. Mutagenic Effect of Sodium Azide on Seed Germination of Eruca sativa (L.) Aust J Basic Appl Sci 3(4): 3081-3087.

Khan, S., Wani, M. R., and Parveen, K. 2004. Induced genetic variability for quantitative traits in Vigna radiate (L.) Wilczek. Pak J Bot 36: 845-850.

Kleinhofs, A., Owais, W. I., and Nilan, R. A. 1978. Azide. Mutat. Res. 55: 165-195.

Kumar, G., and Rai, P. 2007. EMS Induced Karyomorphological Variations in Maize (Zea mays L.) Inbreds. Turk. J. Biol. 31: 187-195.

Kumar, P. R. 1972. Radiation induced variability in improvement of Brown Sarson. Radiation Botany 12(5): 309-313.

Kumar, S., and Dubey, D. K. 1998. Effect of gamma rays EMS and DES on meiosis in Lathyrus sativus. J. Cytol. Genet. 33: 139-147.

Mahla, S. V. S., Mor, B. R., and Yadava, J. S. 1990. Effect of mutagenes on yield and its component characters in mustard. Haryana Agricultural University Journal of Research 8(2): 173-173.

McClintok, B. 1941. The stability of broken ends of chromosome in Zea mays. Genetics 26: 234-282.

Micke, A., Donini, B., and Maluszynski, M. 1987. Induced mutations for crop improvement-A review. Tropical Agriculture (Trinidad) 64:259-278.

Misra, R. C., Mohapatra, B. D., and Panda, B. S. 2001. High yielding mutants of blackgram variety PH-25. Mutation Breeding Newsletter 45: 39.

Mostafa, G. G. 2011. Effect of sodium azide on the growth and variability induction in Helianthus annuus L. Int. J. Plant Breed. Genet. 5: 76-85.

Natrajan, A. T., and Shivshankar, G. 1965. Studies on modification of mutations responses of barley seeds to ethyle methane sulphonate on the fertility of barley. Radiation Botany 7: 7-15.

Patil, B. C., and Bhat, G. I. 1992. A comparative study of MH and EMS in the induction of chromosomal aberrations on lateral root meristem in Clitoria ternatea L. Cytologia 57: 259-264.

Rachovska, G., and Dimova, D. 2000. Effect of sodium azide and gamma rays on $\mathrm{M}_{1}$ quantitative characteristics of the productivity and their connection with $\mathrm{M}_{2}$ mutation changes in winter common wheat. Rasteniev dni-Nauki 37: 413419.

Raicu, P., and Mixich, F. 1992. Cytogenetic effects of sodium azide encapsulated in liposomes on heteroploides cell cultures. Mutat. Res. 283: 215-219.

Rakow, R., and Raney, J. P. 2003. Present status and future perspectives of breeding for seed quality in brassica oilseed crops. In: Soerensen, H., Soerensen, J. C., Muguerza, N. B., and Soerensen, S. (eds.). Proceedings of the $11^{\text {th }}$ International Rapeseed Congress Copenhagen. Royal Veterinary and Agricultural University, Frederiksberg. pp. $181-185$.

Reddi, T. V. V. S. 1977. Cytogenetics of mutants induced by physical and chemical mutagens in three varieties of rice (Oryzasativa L.). Ph.D. Thesis, Andhra University. Waltair.

Rehman, A. 1990. Evolution of improved varieties of rapeseed mustard and sesame through induced mutations. In: Amano, E., and Ashiri, A. (eds.). Mutations breeding of oilseed crops. FAO/IAEA, Vienna. pp.57-67.

Rines, H. W. 1985. Sodium azide mutagenesis in diploid and hexaploid oats and comparison with ethyl methanesulfonate treatments. Environ. Exp. Bot. 25: 7-16.

Sato, M., and Gaul, H. 1967. Effect of ethylene methane sulphonate on the fertility of barley. Radiation Botany 7: 7-15.

Saylor, L. G., and Smith, B. N. 1996. Meiotic irregularities in species of interspecific hybrids in Pinus. Am. J. Bot. 5: 453468. 
Seneviratne, K. A. C. N., and Wijesundara, D. S. A. 2007. First African violets (Saintpaulia ionantha, H. Wendl.) with a changing colour pattern induced by mutation. American Journal of Plant Physiology 2: 233-236.

Singh, M., and Chaturvedi, S. N. 1987. Effectiveness and efficiency of mutagens alone or in combination with dimethyl sulphoxide in Lathyrus sativus L. Indian Journal of Agricultural Science 57(7): 503-507.

Singh, Y. N. 1992. Kava: an overview. J Ethnopharmacol 37: 13-45.

Sinha, S. S. N., and Godward, M. B. E. 1972. Radiation studies in Lens culinaris. Indian J Genet Plant Breed 32: 331-339.

Soheir, E-K., Antoinette. H., and Arif, H. 1989. Cytological effect of herbicide Garlon-4 on root mitosis of Allium cepa. Cytologia 54: 465-472.

Souza, A. M., and Pagliarini, M.S. 1996. Spontaneous chromosome stickiness in canola. Nucleus Calcutta 39: 85-89.

Srivastava, A., and Kapoor, K. 2008. Seed yield is not impaired by chromosome stickiness in sodium azide treated Trigonella foenum-graecum. Cytologia 73(2): 115-121.

Tarar, J. L., and Dnyansagar, V. R. 1980. Comparison of ethyl methane sulphonate and radiation induced meiotic abnormalities in Turnera ulmifolia Linn. var. angustifolia wild. Cytologia 45: 221-231.

Veleminsky, J., and Anglis, K. J. 1987. Effect of sodium azide on replicative and repair DNA synthesis in barley embryos. Mutat. Res. 190: 125-129.

Zhang, B. H. 2000. Regulation of plant growth regulators on cotton somatic embryogenesis and plant regeneration. Biochemistry 39: 1567. 